\title{
STATUS NUDIBRANCHIA DI PERAIRAN PANTAI DESA TEEP MINAHASA SELATAN DAN SELAT LEMBEH BITUNG
}

\author{
(Statue of Nudibranchia at Teep Village South Minahasa Coast and Lembeh \\ Strait Bitung)
}

Faldy Pungus $^{1 *}$, Georis J. F. Kaligis ${ }^{1}$, Medy Ompi ${ }^{1}$

1. Program Studi IImu Kelautan, Fakultas Perikanan dan IImu Kelautan, Universitas Sam Ratulangi, Manado.

*e-mail: faldhileon@gmail.com

The purpose of the research are 1) to indentified Nudibrancia species in Lembeh Strait Bitung and Teep Village South Minahasa Coast. 2) to known Nudibranchia abudance in Lembeh Strait Bitung and Teep Village South Minahasa Coast. The results showed that 10 species of Nudibrancia were found in Teep Village South Minahasa Coast such as Chromodoris annae, Dorisprismatica atromarginata, Glossodoris cincta, Goniobranchus reticulatus, Nembrotha kubaryana, Phyllidia coelestis, Phyllidia picta, Phyllidia varicosa, Phyllidiela nigra, Phyllidiela pustulosa and 11 species were found in Lembeh Strait such as Chromodoris annae, Discodoris boholiensis, Goniobranchus hintuanensis, Goniobranchus verrieri, Hypselodoris sp, Hypselodoris infucata, Hypselodoris tyroni, Hyspelodoris zephyra, Phyllidia picta, Phyllidiela pustulosa, Tambja gabrielae. In Teep Village South Minahasa Coast, Phyllidiela pustulosa was found 6 individu with high density $2 \mathrm{ind} / 500 \mathrm{~m}^{2}$ and the second high density was Phyllidiela nigra, 3 individu with density 1 ind/500 $\mathrm{m}^{2}$. Then, another 8 species, each was found only 1 individu with density $0,33 \mathrm{ind} / 500 \mathrm{~m}^{2}$. In Lembeh Strait, 2 species, Goniobranchus hintuanensis and Phyllidiela pustulosa had high density, each has 3 individu with density 1 ind/500 m². Genus of Hypselodoris had next high density with 2 individu, density $0,67 \mathrm{ind} / 500 \mathrm{~m}^{2}$. Another 5 species which was Chromodoris annae, Discodoris boholiensis, Goniobranchus verrieri, Phyllidia picta and Tambja gabriela, each species was $0,33 \mathrm{ind} / 500 \mathrm{~m}^{2}$.

Keywords : Nudibranchia, Abudance, Species.

Penelitian ini bertujuan 1) mengidentifikasi jenis-jenis Nudibranchia di Perairan Selat Lembeh Bitung dan Pantai Desa Teep Minahasa Selatan. 2) mengetahui kelimpahan Nudibranchia di wilayah perairan Selat Lembeh Bitung dan Pantai Desa Teep Minahasa Selatan. Jenis Nudibranchia yang ditemukan di Perairan Desa Teep Minahasa Selatan ada 10 spesies yaitu Chromodoris annae, Dorisprismatica atromarginata, Glossodoris cincta, Goniobranchus reticulatus, Nembrotha kubaryana, Phyllidia coelestis, Phyllidia picta, Phyllidia varicosa, Phyllidiela nigra, Phyllidiela pustulosa dan Perairan Selat Lembeh ada 11 spesies yaitu Chromodoris annae, Discodoris boholiensis, Goniobranchus hintuanensis, Goniobranchus verrieri, Hypselodoris sp, Hypselodoris infucata, Hypselodoris tyroni, Hyspelodoris zephyra, Phyllidia picta, Phyllidiela pustulosa, Tambja gabrielae. Perairan Desa Teep Minahasa Selatan ditemukan Phyllidiela pustulosa dengan jumlah 6 individu yang memiliki kepadatan spesies 2 ind $/ 500 \mathrm{~m}^{2}$ dan, sedangkan kepadatan kedua tertinggi yaitu spesies Phyllidiela nigra berjumlah 3 individu dengan kepadatan $1 \mathrm{ind} / 500 \mathrm{~m}^{2}$. Kemudian 8 jenis lainnya, masing-masing species ditemukan 1 individu saja dengan kepadatan 0,33 ind/500 $\mathrm{m}^{2}$. Perairan Selat Lembeh ada 2 spesies yang banyak ditemukan yaitu Goniobranchus hintuanensis dan Phyllidiela pustulosa dengan masing-masing individu 3 serta memiliki kepadatan spesies 1 ind/500 $\mathrm{m}^{2}$, sedangkan tingkat kepadatan kedua tertinggi ada pada semua genus Hypselodoris yang memiliki jumlah individu yang sama yaitu 2 individu dengan kepadatan 0,67 ind/500 $\mathrm{m}^{2}$. Kemudian 5 spesies lainnya yaitu Chromodoris annae, Discodoris boholiensis, Goniobranchus verrieri, Phyllidia picta dan Tambja gabriela, masing-masing species memiliki kepadatan $0,33 \mathrm{ind} / 500 \mathrm{~m}^{2}$.

Kata Kunci : Nudibranchia, Kepadatan, Spesies. 


\section{PENDAHULUAN}

Kekayaan hayati laut Indonesia dikenal sangat beragam, salah satu di antaranya adalah Moluska (Purba,2007). Moluska adalah filum terbesar kedua yang menempati laut Indonesia maupun dunia. Setiap kelas Moluska memiliki ciri dan keunikan tersendiri yang digunakan sebagai mencari makanan ataupun berlindung dari predator.

Nudibranchia adalah moluska tidak bercangkang anggota dari Subkelas Opisthobranchia (Kelas gastropoda) (Dayrat, 2006). Kelompok hewan laut ini adalah salah satu kelompok yang menarik untuk diamati karena mempunyai warna yang mencolok dan bentuknya bervariasi (Wägele dan Klussmann- Kolb, 2005).

Tubuh Nudibranchia terdiri dari kulit, otot dan organ tubuh karena telah menanggalkan cangkang pada jutaan tahun yang lalu (Debelius, 2004). Sejauh ini telah diketahui lebih dari 3000 jenis Nudibranchia yang hidup pada perairan dangkal, terumbu karang (Aiken, 2003) dan dapat dijumpai diberbagai tipe habitat mulai dari substrat berpasir, substrat alga, substrat bebatuan sampai substrat karang. Hewan ini mampu berkembang biak di perairan hangat maupun dingin, bahkan di sekitar cerobong gunung api dalam laut.

Gastropoda ini sebenarnya dapat dimakan manusia setelah kandungan racunnya dihilangkan. Penduduk Chile dan penduduk yang tinggal di pulau di seberang Rusia dan Alaska memanggang, merebus atau bahkan memakan beberapa jenis Nudibranchia ini mentah-mentah (Holland, 2008). Nudibranchia juga memiliki potensi sebagai antivirus dan antikanker yang telah mendorong para peneliti untuk mengeksplorasinya (Murniasih, 2005).

Nudibranchia pada umumnya memakan algae, sponge, karang keras dan lunak, bryozoans, serta hydroids. Keberadaan Nudibranchia sebagai salah satu kekayaan hayati Indonesia dan memiliki peran dalam rantai makanan, telah menempatkan Nudibranchia sebagai spesies yang harus dijaga kelestariannya.

Informasi Nudibranchia di perairan tropis umumnya perairan laut sulawesi utara dan sekitarnya adalah relatif sedikit, di mana sampai saat ini ada 2 penelitian, seperti yang dilaporkan oleh Purba (2007), dan Purba, dkk (2013). Mengingat perannya dalam rantai makanan serta menjadi daya tarik bagi para wisatawan dan peneliti untuk menjadi biota yang menarik dinikmati keindahan warnawarni tubuhnya, maka telah mendorong untuk dilakukan penelitian mengenai Nudibanchia untuk skripsi ini.

Nudibranchia adalah organisme yang termasuk dalam filum Moluska, Sub kelas Opistobranchia. Kata Nudibranchia berasal dari bahasa Latin nudus yang berarti telanjang, dan bahasa Yunani brankhia yang berarti insang. Tubuhnya lunak, permukaan tubuh ada yang kasar dan ada sebagian yang licin. Umumnya memiliki kombinasi warna merah, kuning, biru, hijau dan jingga (Purba, 2007).

Secara garis besar tubuh Nudibranchia terdiri dari : mantel, rhinophores, insang, kaki dan organ reproduksi.

\section{Mantel}

Pada semua Nudibranchia, mantel hanya ada pada saat dalam keadaan larva. Ketika sudah dewasa mantel digantikan oleh kulit dan operkulum. Mantel tebal mereka meluas dari atas kaki dan mnebentuk gumpalan kecil (tubercles) dengan berbagai macam ukuran, bentuk dan jenis. Nudibranchia mempunyai banyak warna-warni mantel membuat mereka mudah untuk dilihat. Di sekitar garis tepi mantel, kadang-kadang ditemukan kelenjar racun, digunakan sebagai suatu senjata penghalang pada ikan atau organisme lain yang ingin memangsanya (Anonim, 1997). 
2. Rhinophores

Sebagian besar Opishtobranchia memiliki sepasang organ alat penciuman yang menyerupai tentakel yang disebut 'Rhinophores' yang terletak diatas dorsal pada bagian daerah kepala. 'Rhinophores' kadangkadang berputar membentuk lingkaran digunakan untuk mendeteksi bahan kimia di dalam air yang ingin masuk kedalam tubuh mereka. Kalau diamati lekat sensor ini kelihatan seperti antena yang dapat digunakan untuk menerima gelombang elektromagnetis atau isyarat (Adipati, 1999).

3. Insang

Nudibranchia memiliki insang eksternal atau cerata yang digunakan untuk bernafas, letaknya berada pada bagian belakang. Insang adalah suatu struktur ringan dan lembut seperti bulu melingkupi bagian pelepasan kadangkadang berbentuk selebaran tunggal atau dengan cabang sisi lebih kecil (Anonim, 1997).

\section{Kaki}

Semua Nudibranchia mempunyai kaki yang meluas di sepanjang tubuh. Sangat kuat dan mampu bertahan dari arus pada saat menempel di substrat. Kaki dapat digunakan untuk berenang ketika mereka harus lepas atau temukan makanan. Kaki ini terletak pada bagian lateral dan ventral yang mengenai sirip perut (Anonim, 1997).

\section{Organ reproduksi}

Reproduksi Nudibranchia terjadi secara seksual seperti pada umumnya hewan-hewan yang terdapat dalam Opisthobranchia. Sistem reproduksi pada Nudibranchia dibagi dalam dua bagian yaitu 'Aeolid' Nudibranchia dan 'Dorid' Nudibranchia. Perbedaan pada sistem reproduksi ini terletak pada organ reproduksinya. Pada sistem reproduksi 'Aeolid' tidak terdapat 'caputalory bursa' yang menyerupai kantung dan memiliki fungsi sebagai tempat cairan kental dari hasil kopulasi, sedangkan pada 'Dorid' memiliki 'capulatory bursa' (Schemekel, 1971). berikut:

Klasifikasi Nudibranchia sebagai

Kingdom: Animalia

Phylum: Mollusca

Class: Gastropoda

Subclass: Opisthobranchia

Order: Nudibranchia

Suborder: Doridina

Family: Chromodorididae

Family: Phylididae

Family: Polyceridae

Family: Discodorididae

\section{METODE PENELITIAN}

Waktu yang diperlukan dalam melaksanakan penelitian ini yaitu mulai dari rencana penelitian sampai pada pelaksanaan ujian adalah \pm 5 bulan yaitu dari bulan Desember 2016 sampai bulan April 2017.

Penelitian ini dilakukan di Pantai Desa Teep Minahasa Selatan dengan terletak pada 1011'43.28" LU dan 12430'41.72" BT. Desa Teep Minahasa Selatan merupakan desa pesisir yang sebagian besar masyarakat memiliki mata pencaharian sebagai nelayan.

Pengambilan data Nudibranchia dilakukan juga pada Selat Lembeh Kota Bitung, Provinsi Sulawesi Utara. Selat Lembeh dikenal oleh penyelam karena merupakan lokasi pilihan bagi para penyelaman 'mucky diving' yang terfavorit di Indonesia. Secara geografis Selat Lembeh terletak pada $1^{\circ} 20^{\prime} 25.6^{\prime \prime}$ LU dan 125'14'03.2" BT. Secara umum, dasar laut Selat Lembeh didominasi oleh endapan pasir vulkanis berwarna abu-abu kehitaman dan hanya sebagian kecil yang berpasir putih.

Metode yang digunakan dalam penelitian ini adalah metode survei. Menurut Hamdi dan Baharudin (2012), survei adalah suatu penelitian yang dilakukan dengan cara mengumpulkan data dan menafsirkan data secara umum sebagai apa yang tersedia di lapangan. Alat dan bahan yang digunakan adalah Alat Selam/SCUBA, kamera underwater (Canon G12 dan 
Canon IXUS 10), roll meter $100 \mathrm{M}$, plastik sampel, kamera digital, alat tulis menulis dan buku panduan identifikasi Nudibranchia (Nudibranchia \& Sea Slug Identification Indo-Pacific) (Gosliner et al, 2015).

Pengambilan data dilakukan dengan :

1. Menyusuri garis pantai dengan posisi pulau terletak sebelah kiri, kemudian sampel target dicari dengan 2 orang penyelam SCUBA. Jarak antara garis pantai sampai ke lokasi pengambilan data $\pm 100 \mathrm{~m}$.

2. Penyelam pertama menarik transek sepanjang $50 \mathrm{~m}$ di sekitar kedalaman $\pm 8 \quad \mathrm{~m}$, kemudian penyelam kedua mulai melakukan pencarian siput Nudibranchia di sepanjang garis transek, dengan lebar kiri ada $5 \mathrm{~m}$ dan lebar ke kanan juga ada $5 \mathrm{~m}$, dengan luas area $500 \mathrm{~m}^{2}$. Pencarian sampel dilakukan secara zig-zag. Ada 3 transek yang adalah sebagai ulangan diletakkan pada masingmasing perairan. Jarak antara transek adalah 20 meter.

3. Selanjutnya, sampel termasuk substrat tempat dimana Nudibranchia berada yang ditemukan, difoto dengan menggunakan kamera underwater untuk keperluan identifikasi dan dokumentasi.

4. Selanjutnya hasil foto diidentifikasi dengan menggunakan buku oleh Gosliner dkk (2015) di Laboratorium Biologi Kelautan Fakultas Perikanan dan IImu Kelautan UNSRAT.

Identifikasi Nudibranchia

dilakukan dengan buku panduan identifikasi Nudibranchia (Gosliner et al,2015). Adapun identifikasi Nudibranchia didasarkan pada warna baik pada notum, 'rhinophore', insang , kaki. Kemudian ukuran tubuh (mm), tipe substrat dan kedalaman.

Kelimpahan dapat diukur dengan dua cara (Krebs,1989), yaitu kepadatan dan kepadatan relatif, tetapi dalam penelitian ini digunakan kepadatan. Dalam penelitian ini luas area adalah $500 \mathrm{~m}^{2}$, dengan formula sebagai berikut :

Kepadatan (ind/luas area) $=$

$$
\text { Jumlah Individu Tiap Spesies }
$$

$$
\text { Luas Daerah Sampling }
$$

\section{HASIL DAN PEMBAHASAN}

Jenis-jenis Nudibranchia yang ditemukan di Pantai Desa Teep Minahasa Selatan sebanyak 17 individu terdistribusi pada 3 famili berbeda yaitu Chromodorididae, Phylididae dan Polyceridae.

Adapun spesies tersebut terlihat pada tabel berikut :

Tabel 1. Nudibranchia selat Lembeh

\begin{tabular}{clc}
\hline No. & \multicolumn{1}{c}{ Nama Spesies } & $\begin{array}{c}\text { Jumlah } \\
\text { Individu }\end{array}$ \\
\hline 1. & Chromodoris annae & 1 \\
2. & $\begin{array}{l}\text { Dorisprismatica } \\
\text { atromarginata }\end{array}$ & 1 \\
3. & Glossodoris cincta & 1 \\
4. $\quad$ Goniobranchus & 1 \\
5. $\quad$ Neticulatus & \\
6. Phbrotha kubaryana & 1 \\
7. Phyllidia coelestis & 1 \\
8. & Phyllidia varicta & 1 \\
9. & Phyllidiela nigra & 1 \\
10. Phyllidiela pustulosa & 3 \\
\hline
\end{tabular}

\begin{tabular}{|c|c|c|}
\hline No. & Nama Spesies & $\begin{array}{l}\text { Jumlah } \\
\text { Individu }\end{array}$ \\
\hline 1. & Chromodoris annae & 1 \\
\hline 2. & Discodoris boholiensis & 1 \\
\hline 3. & $\begin{array}{l}\text { Goniobranchus } \\
\text { hintuanensis }\end{array}$ & 3 \\
\hline 4. & Goniobranchus verrieri & 1 \\
\hline 5. & Hypselodoris sp & 2 \\
\hline 6. & Hypselodoris infucata & 2 \\
\hline 7. & Hypselodoris tyroni & 2 \\
\hline 8. & Hyspelodoris zephyra & 2 \\
\hline 9. & Phyllidia picta & 1 \\
\hline 10. & Phyllidiela pustulosa & 3 \\
\hline 11. & Tambja gabrielae & 1 \\
\hline
\end{tabular}

Tabel 2. Nudibranchia desa Teep 
terdistribusi pada 4 famili berbeda yaitu Chromodorididae, Discodorididae, Polyceridae dan Phyllidiidae. Adapun spesies yang ditemukan dapat dilihat pada Tabel 2.

Penelitian ini mengidentifikasi ada 10 spesies ditemukan di perairan Desa Teep Minahasa Selatan, dan ada 11 spesies ditemukan di perairan Selat Lembeh Bitung. Nudibranchia yang ditemukan dikedua daerah ini relatif tinggi dibandingkan dengan jumlah spesies ditemukan di perairan Desa Waleo (Laut Maluku) ada 6 spesies, dan Perairan Desa Kalasey dengan 3 jenis (Purba dkk 2013). Namun demikian kepadatan dikedua lokasi penelitian ini adalah relatif rendah dibandingkan dengan yang kepadatan spesies yang ditemukan di perairan Desa Lewo Laut Maluku dan perairan Desa Kalasey Semenanjung Minahasa, seperti yang dilaporkan oleh Purba $d k k(2013)$.

Kondisi lingkungan, seperti yang dilaporkan oleh Kaligis \& Ompi (2016) kemungkinan menjadi salah satu yang menyebabkan adanya perbedaan kehadiran spesies invertebrata laut. Kedua peneliti ini melaporkan misalnya untuk spesies karang, dimana jumlah spesies karang yang ada di intertidal Desa Teep Minahasa Selatan adalah lebih rendah dari yang ditemukan di subtidal dilokasi yang sama. Kondisi lingkungan, seperti yang dilaporkan oleh Kaligis \& Ompi (2016) dapat pula menjadi faktor yang menentukan adanya variasi spesies Nudibranchia di kedua lokasi. Selat lembeh yang ditemukan 11 spesies Nudibranchia adalah lebih tertutup dibandingkan dengan perairan Desa Teep dengan 10 spesies Nudibranchia.

Pada kedua lokasi penelitian ini, ditemukan famili yang paling banyak yaitu Phyllidiidae dengan jumlah 5 spesies antara lain, Phyllidiela pustulosa, Phyllidiela nigra, Phyllidia picta, Phyllidia varicosa dan Phyllidia coelestis.

Famili Phyllidiidae merupakan salah satu jenis nudibranchia yang umum dijumpai didaerah tropis dan di wilayah Indo-Pacific serta melimpah saat siang hari (Brunckhorst, 1993).

$$
\text { Pada lokasi Desa Teep }
$$

Minahasa Selatan spesies yang paling banyak ditemukan yaitu $P$. pustulosa yang keseluruhannya spesies ditemukan pada ketiga transek. Kemudian spesies $P$. nigra ditemukan kedua terbanyak yang menempati transek 1 dan transek 3. Setelah itu diikuti oleh delapan spesies lainnya.

Spesies $P$. pustulosa memiliki kepadatan tinggi, yaitu 2 ind $/ 500 \mathrm{~m}^{2}$, kemudian diikuti oleh Phyllidiela nigra dengan kepadatan 1 ind $/ 500 \mathrm{~m}^{2}$, dan ada 8 spesies yang masing-masing memiliki kepadatan 0.33 ind $/ 500 \mathrm{~m}^{2}$.

Dilihat dari kepadatan individu pada perairan Desa Teep Minahasa Selatan tampak jenis $P$. pustulosa memiliki jumlah individu paling banyak dengan jumlah 6 individu.

Tabel 3. Kepadatan spesies desa Teep

\begin{tabular}{|c|c|c|c|}
\hline No & Nama Spesies & $\begin{array}{l}\text { Jumlah } \\
\text { Individu }\end{array}$ & $\begin{array}{c}\mathrm{K} \\
\text { (ind/500 } \\
\mathrm{m}^{2} \text { ) }\end{array}$ \\
\hline 1 & $\begin{array}{l}\text { Chromodoris } \\
\text { annae }\end{array}$ & 1 & 0,33 \\
\hline 2 & $\begin{array}{l}\text { Dorisprismatica } \\
\text { atromarginata }\end{array}$ & 1 & 0,33 \\
\hline 3 & $\begin{array}{l}\text { Glossodoris } \\
\text { cincta }\end{array}$ & 1 & 0,33 \\
\hline 4 & $\begin{array}{l}\text { Goniobranchus } \\
\text { reticulatus }\end{array}$ & 1 & 0,33 \\
\hline 5 & $\begin{array}{l}\text { Nembrotha } \\
\text { kubaryana }\end{array}$ & 1 & 0,33 \\
\hline 6 & $\begin{array}{l}\text { Phyllidia } \\
\text { coelestis }\end{array}$ & 1 & 0,33 \\
\hline 7 & Phyllidia picta & 1 & 0,33 \\
\hline 8 & $\begin{array}{l}\text { Phyllidia } \\
\text { varicosa }\end{array}$ & 1 & 0,33 \\
\hline 9 & Phyllidiela nigra & 3 & 1 \\
\hline 10 & $\begin{array}{l}\text { Phyllidiela } \\
\text { pustulosa }\end{array}$ & 6 & 2 \\
\hline
\end{tabular}

$\mathrm{K}=$ Kepadatan 
Tabel 4. Kepadatan spesies selat Lembeh

\begin{tabular}{|c|c|c|c|}
\hline No & Nama Spesies & $\begin{array}{l}\text { Jumlah } \\
\text { Individu }\end{array}$ & $\begin{array}{c}\mathrm{K} \\
\text { (ind/500 } \\
\mathrm{m}^{2} \text { ) }\end{array}$ \\
\hline 1 & $\begin{array}{l}\text { Chromodoris } \\
\text { annae }\end{array}$ & 1 & 0,33 \\
\hline 2 & $\begin{array}{l}\text { Discodoris } \\
\text { boholiensis }\end{array}$ & 1 & 0,33 \\
\hline 3 & $\begin{array}{l}\text { Goniobranchus } \\
\text { hintuanensis }\end{array}$ & 3 & 1 \\
\hline 4 & $\begin{array}{l}\text { Goniobranchus } \\
\text { verrieri }\end{array}$ & 1 & 0,33 \\
\hline 5 & Hypselodoris sp & 2 & 0,67 \\
\hline 6 & $\begin{array}{l}\text { Hypselodoris } \\
\text { infucata }\end{array}$ & 2 & 0,67 \\
\hline 7 & $\begin{array}{l}\text { Hypselodoris } \\
\text { tyroni }\end{array}$ & 2 & 0,67 \\
\hline 8 & $\begin{array}{l}\text { Hyspelodoris } \\
\text { zephyra }\end{array}$ & 2 & 0,67 \\
\hline 9 & Phyllidia picta & 1 & 0,33 \\
\hline 10 & $\begin{array}{l}\text { Phyllidiela } \\
\text { pustulosa }\end{array}$ & 3 & 1 \\
\hline 11 & $\begin{array}{l}\text { Tambja } \\
\text { gabrielae }\end{array}$ & 1 & 0,33 \\
\hline
\end{tabular}

$\mathrm{K}=$ Kepadatan

Nudibranchia yang ditemukan di perairan Selat lembeh Bitung, dimana ada 2 spesies, yaitu $G$. hintuanensis dan $P$. pustulosa, masing-masing memiliki kepadatan yang tinggi, yaitu 1 ind/500 $\mathrm{m}^{2}$, selanjutnya diikuti oleh 4 spesies lainnya, yaitu Hypselodoris sp, Hypselodoris infucata, Hypselodoris tyroni, dan Hypselodoris zephyra, yang masing-masing memiliki kepadatan 0,67 ind $/ 500 \mathrm{~m}^{2}$. Ada 5 spesies memiliki kepadatan rendah, yaitu Chromodoris annae, Discodoris boholiensis, Goniobranchus verrieri, $P$. picta dan Tambja gabrielae, masingmasing memiliki kepadatan 0,33 ind/500 $\mathrm{m}^{2}$. Hampir keseluruhan spesies berada pada substrat pasir, sedangkan hanya 2 spesies saja yang ditemukan pada substrat karang. Hal ini dimungkinkan karena dasar laut Selat Lembeh rata-rata memiliki substrat berpasir vulkanis yang berwarna abuabu kehitaman.
Pada perairan ini (Selat Lembeh) ada 2 spesies yang terlihat paling banyak ditemukan yaitu $P$. pustulosa dan $G$. hintuanensis yang masing-masing memiliki jumlah 3 individu. Jenis $P$. pustulosa pada lokasi ini ditemukan hanya 3 individu, berbeda dengan Desa Teep Minahasa Selatan yang memiliki 6 individu. Sedangkan untuk spesies $G$. hintuanensis tak ditemukan sama sekali pada perairan Desa Teep Minahasa Selatan.

Perbedaan kelimpahan dapat disebabkan oleh faktor-faktor seperti waktu rekruitmen dan predator. Rekruitmen invertebrata dapat berhubungan dengan ketersediaan larva di kolom perairan, yang kemungkinan melimpah di kolom perairan disaat puncak pemijahan terjadi, yang dapat berhubungan dengan jumlah larva yang turun ke dasar, yang menempel, terekrut dalam populasi invertebrata dasar (Ompi, 2010), seperti juga Nudibranchia dalam penelitian ini. Pemijahan spesiesspesies invertebrata dapat berbeda sepanjang tahun, seperti untuk spesies tropis kerang box, yang dilaporkan oleh (Ompi, 1997).

Kelimpahan Nudibranchia dalam penelitian ini adalah kurang dibandingkan dengan yang dilaporkan oleh Purba dkk (2013). Invertebrata tropis dapat memijah dan tersedia larva sepanjang tahun dalam Nudibranchia, waktu yang dilaporkan oleh Purba $d k k$ (2013), kemungkinan sebagai waktu untuk memijah yang dapat berhubungan dengan ketersedian jumlah Nudibranchia di kedua lokasi penelitian mereka.

Predator dapat menjadi salah satu pengontrol perbedaan kelimpahan biota invertebrata pada lokasi yang berbeda, seperti gastropoda Lambislambis (Boneka $d k k, 1993)$, dan kerang Oyster Isognomon (Ompi, 1995). Dalam penelitian ini, kurangnya kelimpahan Nudibranchia baik di Desa Teep Minahasa Selatan dan Selat Lembeh Bitung, misalnya dibandingkan di Desa Waleo Laut Maluku (Purba dkk, 
2013), kemungkinan dapat disebabkan pula oleh perbedaan kehadiran predator di lokasi-lokasi penelitian.

\section{KESIMPULAN}

Dari data tersebut dapat disimpulkan bahwa :

1) Perairan Desa Teep Minahasa Selatan ada 10 spesies, yaitu $C$. annae, D. atromarginata, G. cincta, $G$. reticulatus, $N$. kubaryana, $P$. coelestis, $P$. picta, $P$. varicosa, $P$. nigra, $P$. pustulosa, sedangkan pada Perairan Selat Lembeh Bitung ditemukan 11 spesies, yaitu $C$. annae, $\quad D . \quad$ boholiensis, $G$. hintuanensis, $G$. verrieri, Hypselodoris sp, $H$. infucata, $H$. tyroni, $H$. zephyra, P. picta, $P$. pustulosa, T. Gabrielae.

2) Perairan Desa Teep Minahasa Selatan ditemukan spesies $P$. pustulosa yang memiliki kepadatan spesies $2 \mathrm{ind} / 500 \mathrm{~m}^{2}$, spesies $P$. nigra dengan kepadatan 1 ind/500 $\mathrm{m}^{2}$. Kemudian 8 jenis lainnya memiliki kepadatan 0,33 ind/500 $\mathrm{m}^{2}$. Kemudian pada Perairan Selat Lembeh ada 2 spesies yang banyak ditemukan yaitu $G$. hintuanensis dan $P$. pustulosa dengan kepadatan spesies 1 ind $/ 500 \mathrm{~m}^{2}$. Sedangkan untuk Hypselodoris sp , H. infucata, $H$. tryoni, $H$. zephyra memiliki kepadatan 0,67 ind/500 $\mathrm{m}^{2}$. Kemudian 5 spesies lainnya yaitu $C$. annae, D. boholiensis, G. verrieri, $P$. picta dan $T$. gabrielae memilki kepadatan 0,33 ind $/ 500 \mathrm{~m}^{2}$.

\section{DAFTAR PUSTAKA}

Adipati, M. 1999. Keanekaragaman dan Informasi Reproduksi Nudibranchia (Mollusca, Opisthobranchia) Di Teluk
Manado. SKRIPSI FPIK UNSRAT 1999.

Aiken, R.B. 2003. Some aspects of the life history of an intertidal population of the Nudibranch Dendronotus frondosus (Ascanius, 1774) (Opisthobranchia Dendronotoidea) in the bay of fundy. Veliger 46 (2): 169-175.

Anonim. 1997. Okinawa Opisthobranch Taxonomy. Http://www. Taxonomy.html (Diakses pada 13 Oktober 2016 , pukul 4.20 Wita).

Boneka, F. B., Ompi M., Andaki, J.A.P. 1993. Occurrence Of The Common Spider Shell, Lambislambis (L.) (Gastropoda: Strombidae) In The Intertidal Zone Of Karatung, Sangihe Island, Indonesia. Phuket Marine Biological Center Publication 13 :159-161.

Brunckhorst, D. J. 1993. The Systematics and Phylogeny of Phyllidiidae Nudibranchs (Doridoidea). Records of the Australian Museum. Supplement 16: 1-107, pls.1-9, ISBN:0 $73100065 \mathrm{X}$.

Dayrat, B. 2006. A Taxonomic Revision of Paradoris Sea Slugs (Mollusca: Gastropoda: Nudibranchia: Doridina). Zoological Journal of the Linnaean Society 147: 125-238.

Debelius, H. 2004. Nudibranch and Sea Snails IndoPacific Field Guide. IKAN-Unterwasserarchiv, Frankfurt: 320 pp.

Gosliner, T.M.,Valdes, A., Behrens, D.W. 2015. Nudibranchia \& Sea Slug Identification Indo-Pacific. New World Publication. Florida

Hamdi, A.S., Baharuddin, E. 2012. Metode Penelitian Kuantitatif Aplikasi Dalam Penelitian. Deepublisher Publisher. Yogyakarta. 
Holland, J.S. 2008. Warna Warni Kehidupan. NG Indonesia edisi Juni 2008: 80-83.

Kaligis, F. G. J., Ompi, M. 2016. Implementation

Of Environmentally Friendly Monitoring Method:"Green Watch" And "Image Analysis" In Sustainable Resources Utilization In The Coast Community Of Teep, South Minahasa. Platax: Vol 4, No 2. $10 \mathrm{p}$.

Krebs, C. J. 1989. Ecological Methodology. Harper and Row Publisher, New York. 649 pp.

Murniasih, T. 2005. Substansi Kimia untuk Pertahanan Diri dari Hewan Laut Tak Bertulang Belakang. Oseana. 30(2): $19-$ 27.

Ompi, M. 1995. The Tree Oyster Isognomon (Parviperna) Sp.: Effect Of An Aggregated Distribution. Proceedings Of The Fifth Workshop Of The Tropical Marine Mollusc Programme (TMMP): Conducted In Indonesia At Sam Ratulangi University, Manado And Hasannudin University, Ujung Pandang. Phuket Marine Biological Center Special Publication. No 15.161 P.

Ompi, M. 1997. Recruitment of The Box Mussel, Septifer Bilocularis L.: Effect Of Substratum And Adult Density. Tropical Marine Mollusc Programme, Phuket (Thailand).

Ompi, M. 2010. Settlement behaviour and sizes of mussel larvae from the family Mytilidae Branchidontes erosus (Lamarck, 1819), Branchidontes rostratus (Dunker,1857), Trichomya hirsutus (Lamarck,1819), and Mytilus galloprovincialis (Lamarck,1819). Journal of
Coastal Development. Vol 13, No 3.

Purba, A. 2007. Struktur Komunitas Nudibranchia (Mollusca,Opisthobranchia) Di Beberapa Perairan Semenanjung Minahasa Propinsi Sulawesi Utara. SKRIPSI FPIK - UNSRAT 2007.

Purba, A Kusen J. D., Mamangkey, N. G. F. 2013. Struktur Komunitas Gastropoda Nudibranchia Di Perairan Desa Waleo (Laut Maluku) Dan Perairan Desa Kalasey (Teluk Manado, Laut Sulawesi). Journal Aquatic Science \& Management. Vol. 1, No. 1, 21-25. 